УДК 579:546.56:581.1:633.1

\title{
ВЛИЯНИЕ НАНО- И ИОННЫХ ФОРМ МЕДИ НА ПИГМЕНТНЫЙ СОСТАВ ПШЕНИЦЫ ОБЫКНОВЕННОЙ
}

\section{(C) А.М. Короткова}

\author{
Оренбургский государственный университет, пр. Победы, 13, Оренбург, \\ 460000 (Россия), e-mail: AnastasiaPorv@mail.ru
}

\begin{abstract}
Исследована чувствительность фотосинтетического аппарата Triticum vulgare Vill. к воздействию различных концентраций растворов сферических наночастиц (НЧ) меди $\mathrm{Cu}^{0}$ диаметром $84 \pm 5$ нм и сульфата меди (II) $\mathrm{CuSO}_{4}$. Содержание фотосинтетических пигментов (ФП) зависит от вида экзогенного агента, его концентрации и времени экспозиции. Пигментный аппарат пшеницы характеризуется выраженной избирательной чувствительностью к исследованным соединениям. Показано, что устойчивость пигментного аппарата убывает в ряду $\mathrm{Cu}^{0}>\mathrm{CuSO}_{4}$. Причем наиболее чувствительны ФП к 0,1, 0,01, 3, 6 мг/л $\mathrm{Cu}^{0}$ и 0,375, 0,75, 3, 6 мг/л $\mathrm{CuSO}_{4}$.

Ключевые слова: Triticum vulgare, наночастицы, медь, содержание меди, содержание фотосинтетических пигментов, хлорофилл $a$ и $b$, каротиноиды.

Работа выполнена в рамках Государственного задания Министерства образования и науки Российской Федерации на проведение научно-исследовательских работ (Шифр заявки №4.2979.2011).
\end{abstract}

\section{Введение}

В последние десятилетия все сферы антропогенной деятельности сопряжены с понятием наночастиц (НЧ), однако потенциальный риск данных материалов на среду обитания человека до сих пор в полной мере не оценен. Имеются данные, подтверждающие безопасность НЧ в тестах in vitro и in vivo с потенциалом широкого применения в медицине [1-3], однако существуют и не совсем обнадеживающие сведения [4]. В частности, НЧ приводят к увеличению продукции активных форм кислорода и к последующему изменению функций биологических структур [5]. Наряду с этим высокая удельная поверхность НЧ [6] увеличивает вероятность адсорбции на них контаминантов и последующего проникновения в клетки живых организмов, что резко увеличивает токсичность этих веществ [5].

Совокупность научных данных о НЧ указывает на обязательное определение степени их экологической безопасности, в особенности НЧ тяжелых металлов. Наиболее токсичным для высших растений является медь - избыток ее нано- и ионных форм приводит к повреждению тканей, изменению проницаемости мембран, перекисному окислению липидов в мембранах хлоропластов и ингибированию переноса электронов по фотосинтетическому пути [7-9]. Несмотря на большое число исследований по воздействию меди на объекты окружающей среды, данные о влиянии НЧ $\mathrm{Cu}^{0}$ на пигментную систему растений, как критерия оценки воздействия экзогенных факторов, отсутствуют [10-12]. Количественное определение фотосинтетических пигментов (ФП) служит косвенным показателем постстрессового состояния у растений, который можно использовать для фитотестирования загрязнения наномериалами. В связи с этим целесообразно оценить адаптивные реакции, развивающиеся у наиболее чувствительных к соединениям меди растений -

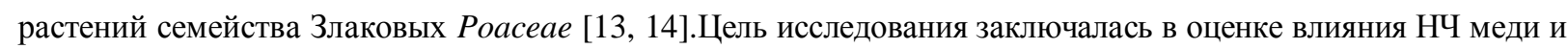

Короткова Анастасия Михайловна - аспирант, научный сотрудник института биоэлементологии, тел.: (35352) 37-24-82, e-mail: anastasiaporv@ mail.ru сульфата меди (II) в диапазоне концентраций от 6 до 0,001 мг/л на содержание ФП в листьях проростков Triticum vulgare Vill. 


\section{Экспериментальная часть}

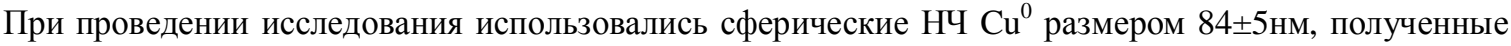
в Институте энергетических проблем химической физики РАН, подробно о получении наночастиц сказано в нашей предыдущей работе [15]. В качестве объекта исследования использовали семена пшеницы обыкновенной Triticum vulgare Vill, купленные в розничном магазине и предназначенные для проращивания в пищевых целях. Перед проращиванием семена дезинфицировали 0,01\%-ным раствором $\mathrm{KMnO}_{4}$ в течение 5 мин и, после трехкратного промывания дистиллированной водой, помещали в пластиковые контейнеры на фильтровальную бумагу по 30 штук. В приготовленные образцы наливали по 5 мл растворов $\mathrm{HЧ}^{0}$ и $\mathrm{CuSO}_{4} \cdot 5 \mathrm{H}_{2} \mathrm{O}$ в концентрациях - 6, 3, 1,5, 1, 0,75, 0,375, 0,1, 0,01 и 0,001 мг/л. Для приготовления растворов точные навески веществ с дистиллированной водой интенсивно диспергировали в течение 15 мин ультразвуком с частотой 35 кГц в источнике ванного типа «Сапфир ТТЦ» (ЗАО ПКФ «Сапфир», Россия). В контрольную пробу помещали дистиллированную воду. Приготовленные подобным образом анализируемые образцы выращивали при естественном освещении и температуре $23 \pm 1{ }^{\circ} \mathrm{C}$ в течение 14 дней. Каждый второй день эксперимента образцы поливали 5 мл дистиллированной воды.

Для получения вытяжки пигментов свежее растительное сырье растирали с добавлением $\mathrm{CaCO}_{3}$, прокаленного кварцевого песка и 3 мл 96\%-ного этилового спирта. Полученную взвесь многократно отфильтровывали до полного извлечения ФП и фотометрировали. Содержание пигментов определяли спектрофотометрическим методом на 4-й, 7-й и 14-й день эксперимента на фотометре КФК-3 (Россия). Оптическую плотность раствора спиртовой вытяжки определяли по стандартной методике при $\lambda=665$ нм (хлорофилл $a), \lambda=649$ нм (хлорофилл $b$ ) и $\lambda=450,5$ нм (сумма каротиноидов) [16]. На 14 день из оставшихся образцов для определения содержания меди формировали аналитические пробы. Для этого от растительного сырья отделяли семена и высушивали в сушильном шкафу при $105{ }^{\circ} \mathrm{C}$ до постоянной массы. Содержание меди в сухой вегетативной массе определяли методом атомно-адсорбционной спектрофотометрии по ГОСТу 30178-96 [17].

Результаты обрабатывали с использованием программы Microsoft Office Excel. Полученные данные, приведенные на рисунках, представляют средние значения из трех биологических повторностей, отклонения составляли $\pm 10-20 \%$.

\section{Обсуждение результатов}

Результаты количественного содержания ФП в побегах пшеницы мягкой под воздействием соединений меди представлены на рисунках 1-3. По динамике содержания зеленых пигментов видно, что содержание хлорофилла $a$ (Хл $a)$ и $b($ Хл $b)$ при воздействии НЧ $\mathrm{Cu}^{0}$ увеличивалось по отношению к контролю на протяжении всего эксперимента при концентрациях свыше 1 мг/л на 18\%, в то время как при концентрациях 0,1 и 0,001 мг/л содержание Хл $b$ было меньше контроля в среднем на 26\% (рис. 1-I, рис. 2-I). Отличная от НЧ, обработка сульфатом меди (II) снижала содержание Хл $a$ и Хл $b$ сразу на 4 день экспозиции в среднем на $32 \%$ (рис. 1-II, рис. 2-II). Хотя к 7-14-му дню уровень пигментов повышался по отношению к контролю при всех анализируемых концентрациях, за исключением концентрации 3 мг/л (здесь содержание Хл $b$ снижалось на 12\%). В проведенных нами опытах наиболее ярко снижение общего содержания каротиноидов по отношению к контролю при экспозиции НЧ $\mathrm{Cu}^{0}$ на $74 \%$ и при экспозиции $\mathrm{CuSO}_{4}$ на $19 \%$ (рис. 3). Полученные нами данные свидетельствуют о возможном изменении ультраструктуры хлоропластов и инициировании окислительного стресса в растительном организме [18]. В связи с тем, что каротиноиды более устойчивы к стрессовым воздействиям и предохраняют хлорофилл от фотоокисления, уменьшение их уровня способствовало восстановлению пула зеленых пигментов [5, 19]. Однако к концу экспериментального периода при воздействии концентраций ниже 0,75 мг/л $\mathrm{Cu}^{0}$ и 6,3 и 0,375 мг/л $\mathrm{CuSO}_{4}$ рост пула желтых пигментов, вероятно, не успевал восполнить количество Хл $a$ и Хл $b$ и их защитная функция ослабевала (рис. 3 ).

Атомно-адсорбционный метод выявил активное накопление тяжелого металла в тестируемом растении по сравнению с фоновым содержанием, особенно при обработке нано- и ионными формами меди в концентрациях свыше 0,75 мг/л: на 1,6-90,3\% - при экспозиции наноформами меди и на 12-82,4\% - при экспозиции ионными формами элемента (рис. 4). Согласно данным анализа при экспозиции НЧ $\mathrm{Cu}^{0}$ в концентрациях свыше 1,5 мг/л наблюдается большая аккумуляция в растении меди (диапазон значений был от 25 до 98 мг/кг сухого веса) по сравнению с $\mathrm{CuSO}_{4}$, напротив, при обработке концентрациями $\mathrm{CuSO}_{4} \mathrm{Huже}$ 
1,5 мг/л наблюдается большее содержание меди (диапазон значений варьировал от 10,8 до 54 мг/кг сухого

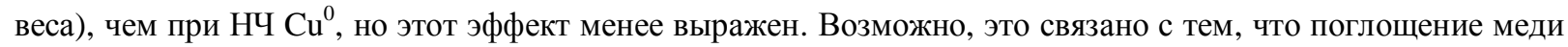
в наноформе осуществляется пассивным транспортом - при более высоких концентрациях, в то время как ее ионная форма при более низких концентрациях - активным транспортом $[13,14,20]$. Несмотря на активное поглощение растениями меди, симптомов медной фитотоксичности при воздействии различных концентраций соединений меди, которые проявляются при содержании в тканях растений выше 2030 мг/кг, не наблюдалось [13, 14, 20, 21].

Интересно отметить, что обработка растений соединениями меди в концентрациях меньше 0,1 мг/л приводила к снижению содержания меди в анализируемом сырье по отношению контролю на 8-35\%, причем степень уменьшения увеличивается с уменьшением концентрации НЧ и сульфата меди (II) (диапазон значений от 7 до 8,8 мг/кг сухого веса). Анализ совокупных данных позволяет предположить, что наиболее

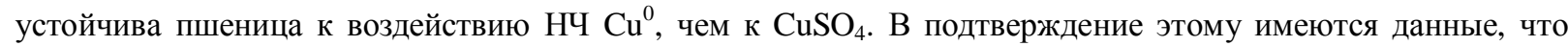
корнями сельскохозяйственных растений лучше поглощается $\mathrm{Cu}^{2+}[20,21]$. К тому же медь легко проникает через плазмалемму без стадии восстановления и быстро передвигается по сосудистым тканям [14]. Напротив, проникновение $\mathrm{HЧ} \mathrm{Cu}^{0}$ размером $84 \pm 5$ нм в корневой чехлик может быть затруднено прочным прикреплением НЧ к клеточной стенки [20] и малым размером пор последних (от 2 до 20 нм) [22].

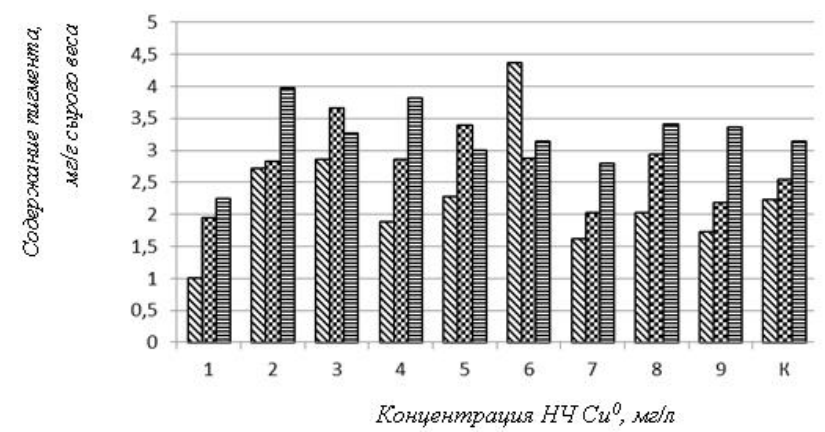

I

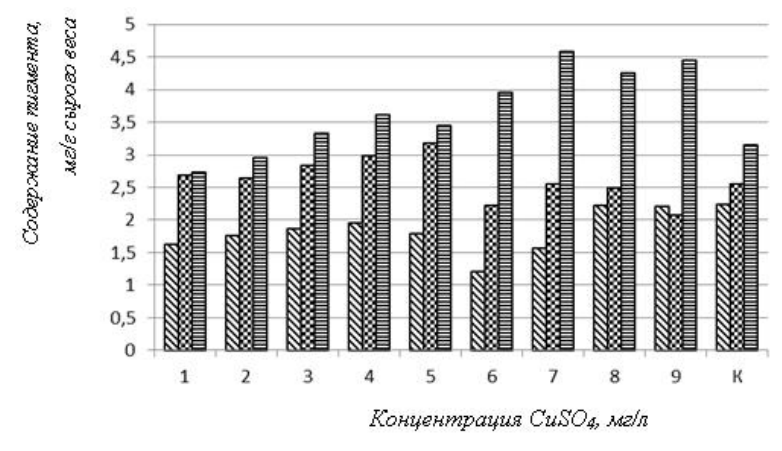

II

Рис. 1. Зависимость содержания Хл $а$ в листьях Triticum vulgare Vill. от времени экспозиции соединениями меди. $\mathbf{1}-6, \mathbf{2}-3, \mathbf{3}-1,5, \mathbf{4}-0,75, \mathbf{5}-0,375, \mathbf{6}-1,7-0,1, \mathbf{8}-0,01, \mathbf{9}-0,001 ; \mathbf{K}$ - контроль. Время экспозиции в днях: $\mathbf{D}-4$-й день, $\mathbf{D}-7$-й день, $=-14$-й день

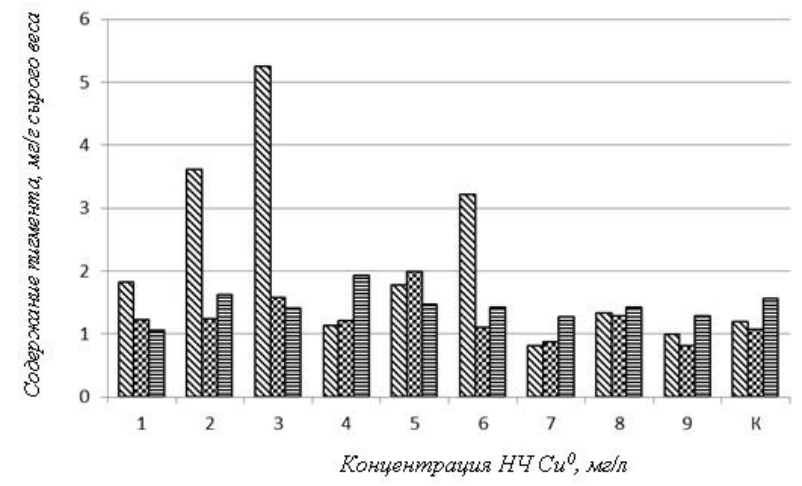

I

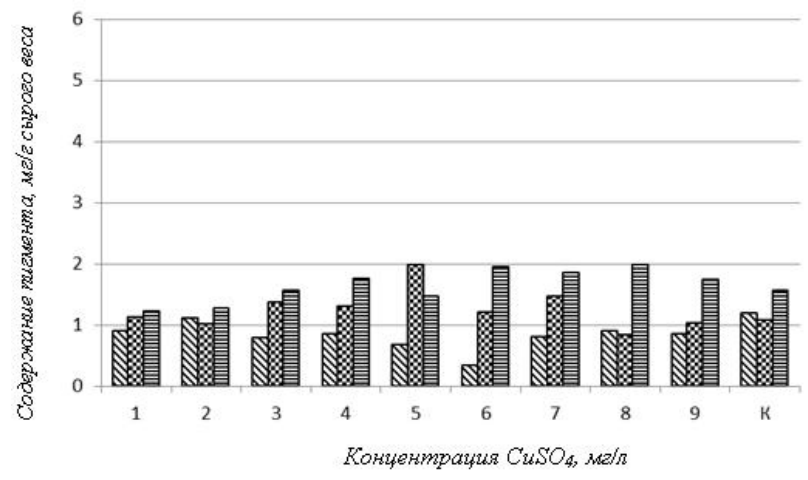

II

Рис. 2. Зависимость содержания Хл $b$ в листьях Triticum vulgare Vill. от времени экспозиции соединениями меди. $\mathbf{1}-6, \mathbf{2}-3, \mathbf{3}-1,5, \mathbf{4}-0,75, \mathbf{5}-0,375, \mathbf{6}-1, \mathbf{7}-0,1, \mathbf{8}-0,01, \mathbf{9}-0,001 ; \mathbf{K}-$ контроль. Время экспозиции в днях: $\mathbf{\nabla}-4$-й день, $\mathbf{\square}-7$-й день, $\Xi-14$-й день 


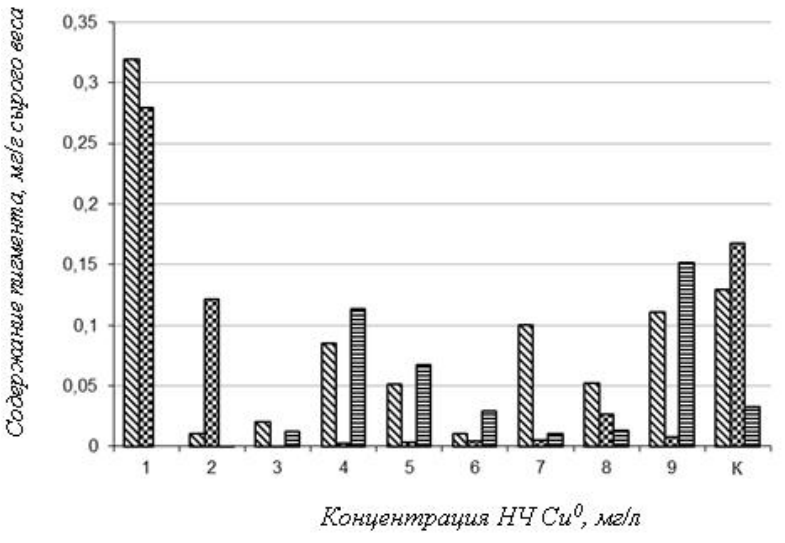

I

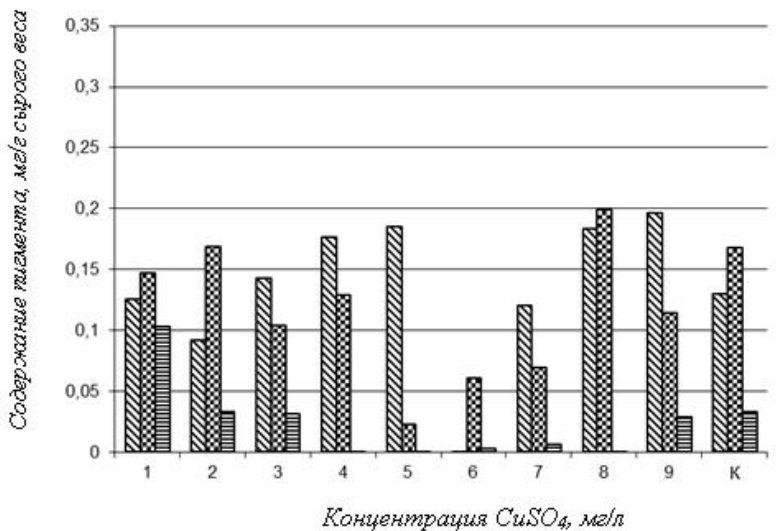

II

Рис. 3. Зависимость содержания каротиноидов в листьях Triticum vulgare Vill. от времени экспозиции соединениями меди. $\mathbf{1}$ - 6, 2 -3, 3 - 1,5, $\mathbf{4}$ - 0,75, 5-0,375, 6-1, 7 - 0,1, 8-0,01, 9-0,001; К - контроль.

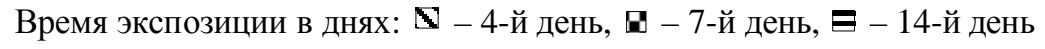

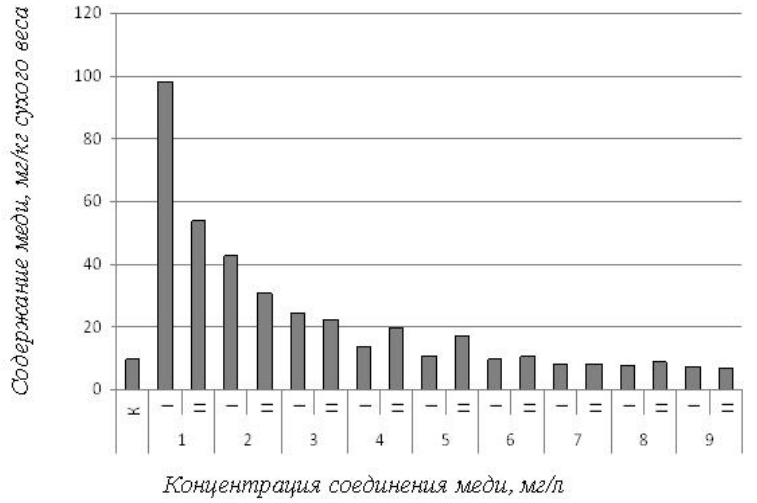

Рис. 4. Зависимость содержания меди в сырье Triticum vulgare Vill. от экспозиции НЧ $\mathrm{Cu}^{0}$ (I) и $\mathrm{CuSO}_{4}$ (II). 1 - 6, 2 - 3, 3 - 1,5, 4 - 0,75, 5-0,375, $\mathbf{6}-1, \mathbf{7}-0,1, \mathbf{8}-0,01, \mathbf{9}-0,001 ; \mathbf{K}-$ контроль

\section{Выводы}

Итак, была предпринята попытка оценить влияние различных концентраций нано- и ионных форм меди на синтез ФП в листьях проростков Triticum vulgare Vill. Содержание ФП зависело от формы соединения меди, его концентрации и времени экспозиции. Все образцы сохраняли способность к синтезу хлорофиллов в присутствии НЧ (значения варьировали в диапазоне от 0,819 до 5,25 мг/г сырого веса) и ионов меди (от 0,347 до 4,588 мг/г сырого веса). Однако показатель содержания ФП в листьях пшеницы, особенно каротиноидов, наиболее чувствителен к присутствию в среде ионной, нежели наноразмерной формы меди. Причем увеличение чувствительности к меди не всегда имеет пропорциональную зависимость от концентрации и наиболее выражено при концентрациях $6>3>0,01>0,1>0,375>1 \quad$ мг/л $\mathrm{HЧ}^{\mathrm{Cu}}$ и $6>0,375>0,75>3>1,5$ мг/л $\mathrm{CuSO}_{4}$.

\section{Список литературы}

1. Чурилов Г.И. Влияние нанопорошков железа, меди, кобальта в системе почва-растение // Вестник ОГУ. №12. 2009. С. 148-151.

2. Чурилов Г.И. Эколого-биологические эффекты нанокристаллических металлов : автореф. дисс. ... докт. биол. наук. Балашиха, 2010. 42 c.

3. Шимановский Н.Л., Епинетов М.А., Мельников М.Я. Молекулярная и нанофармакология. М., 2010. 624 с.

4. Gatti A., Montanari S. Nanopathology: The Health Impact of Nanoparticles. Singapore: Pan Stanford Publishing, 2008. $298 \mathrm{p}$.

5. Анциферова И.В., Зенков А.И., Сомов О.В. Подходы к оценке безопасности наноматериалов: учеб. пособие. Пермь, 2010. 85 c. 
6. Altavilla C., Ciliberto E. Inorganic Nanoparticles: Synthesis, Applications, and Perspectives - An Overview // Inorganic Nanoparticles: Synthesis, Applications, and Perspective. Boca Raton: CRC Press, 2011. Pp. 1-17.

7. Madhava K.V., Raghavendra A.S., Janardhan K. Physiology and Molecular Biology of Stress Tolerance in Plants. Reddy. Springer: Netherlands, 2006. 345 p.

8. Begum G. Ecotoxicology. Croatia: InTech, 2012. 146 p.

9. Montanaro G., Dichio B. Plant Water Relations: Absorption, Transport and Control Mechanisms, Advances in Selected Plant Physiology Aspects. Croatia: InTech, 2012. 388 p.

10. Демидчик В. В., Соколик А. И., Юрин В. М. Токсичность избытка меди и толерантность к нему растений // Успехи современной биологии. 2001. Т. 121, №5. С. 511-525.

11. Розенцвет О.А., Мурзаева С.В., Гущина И.А. Аккумуляция меди и ее влияние на метаболизм белков, липидов и фотосинтетических пигментов в листьях Potamogeton perfolitus L. // Известия Самарского научного центра Российской академии наук. Т. 5, №2. 2003. С. 305-311.

12. Косицына А.А., Макурина О.Н., Нестеров В.Н., Розенцвет О.А. Влияние ионов меди и кадмия на пигментный комплекс водных растений семейства Hydrocharitaceae // Известия Самарского научного центра Российской академии наук. 2010. Т. 12, №1. С. 156-161.

13. Дабахов М.В., Дабахова Е.В., Титова В.И. Экотоксикология и проблемы нормирования. Н. Новгород, 2005. $165 \mathrm{c.}$

14. Кабата-Пендиас А., Пендиас Х. Микроэлементы в почвах и растениях. М., 1989. 439 с.

15. Лебедев С.В., Осипова Е.А., Короткова А.М., Кузьмин С.Н., Кудакаев И.Р. Влияние нанопорошков микроэлементов на морфо-физиологические признаки растения вида Triticum vulgare Vill // Биологическая наука в решении проблем естествознания: мат. Всерос.заоч. НПК. Чебоксары: Чуваш. гос. пед. ун-т, 2013. С. 33-36.

16. Shlyk A.A. On spectrophotometric determination of chlorophylls a and b// Biochemistry. 1968. T. 33. Pp. $275-285$.

17. ГОСТ 30178-96. Сырье и продукты пищевые: атомно-сорбционный метод определения токсичных веществ. Минск: ИПК, 1997.

18. Carter G.A., Knapp A.K. Leaf optical properties in higher plants: linkingspectral characteristics to stress and chlorophyll concentration // American Journal of Botany. 2001. №88. Pp. 677-684.

19. Пешкова А.А., Дорофеев Н.В. Адаптация фотосинтетического аппарата озимой пшеницы в период осеннего развития // Вестник ИрГСХА. 2011. Вып. 45. С. 20-27.

20. Битюцкий Н.П. Микроэлементы и растение: учеб. пособие. СПб., 1999. 232 с.

21. Бингам Ф.Т., Перьа Ф.Д., Джерелл У.М. Токсичность металлов в сельскохозяйственных культурах // Некоторые вопросы токсичности ионов металлов / под ред. Х. Зигеля, А. Зигеля. М., 1993. С. 101-131.

22. Rico C.M., Majumdar S., Duarte-Gardea M., Peralta-Videa J.R., Gardea-Torresdey J.L. Interaction of nanoparticles with edible plants and their possible implications in the food chain // J. Agric Food Chem. №59(8). 2011. Pp. 3485-3498.

Поступило в редакиию 6 декабря 2013 г. 


\section{MON WHEAT}

Korotkova A.M. EFFECT OF NANO- AND ION FORMS OF COPPER ON PIGMENT COMPOSITION OF COM-

Orenburg State University, pr. Pobedy, 13, Orenburg, 460000, (Russia),e-mail: AnastasiaPorv@mail.ru

The sensitivity of the photosynthetic apparatus of Triticum vulgare Vill. to exposure of various concentrations solutions of spherical nanoparticles (NP) copper $\mathrm{Cu}^{0}$ diameter $84 \pm 5 \mathrm{~nm}$ and copper sulfate (II) $\mathrm{CuSO}_{4}$ had been investigated. The content of photosynthetic pigments (PHP) depends on the type of exogenous agent, its concentration and the exposure time. Pigment apparatus of wheat is characterized by severe selective sensitivity to the examined compounds. It is shown that the stability of the pigment apparatus decreases in the line $\mathrm{Cu}^{0}>\mathrm{CuSO}_{4}$. Moreover, the most sensitive PHP to 0,1,0,01, 3,6 mg/l Cu${ }^{0}$ and 0,375 , $0,75,3,6 \mathrm{mg} / \mathrm{l} \mathrm{CuSO}$.

Keywords: Triticum vulgare, nanoparticles, copper, copper content, the content of photosynthetic pigments, chlorophyll $\mathrm{a}$ and $\mathrm{b}$, carotenoids.

\section{References}

1. Churilov G.I. Vestnik $O G U$, 2009, no. 12, pp. 148-151. (in Russ.).

2. Churilov G.I. Jekologo-biologicheskie jeffekty nanokristallicheskih metallov: Avtoref. diss. dokt. biol. nauk. [Ecological and biological effects of nanocrystalline metals. Sc.D. diss]. Balashiha, 2010, 42 p. (in Russ.).

3. Shimanovskij N.L., Epinetov M.A., Mel'nikov M.Ja. Molekuljarnaja i nanofarmakologija. [Molecular and nanopharmacology]. Moscow, 2010, 624 p. (in Russ.).

4. Gatti A., Montanari S. Nanopathology: The Health Impact of Nanoparticles. Singapore, 2008, 298 p.

5. Anciferova I.V., Zenkov A.I., Somov O.V. Podhody k ocenke bezopasnosti nanomaterialov: uchebnoe posobie [Approaches to assessing the safety of nanomaterials: a tutorial]. Perm', 2010, 85 p. (in Russ.).

6. Altavilla C., Ciliberto E. Inorganic Nanoparticles: Synthesis, Applications, and Perspective / Ed. C. Altavilla, E. Ciliberto. Boca Raton: CRC Press, 2011, pp. 1-17.

7. Madhava K.V., Raghavendra A.S., Janardhan K. Physiology and Molecular Biology of Stress Tolerance in Plants. Reddy. Springer: Netherlands, 2006, 345 p.

8. Begum G. Ecotoxicology. Croatia: InTech, 2012, 146 p.

9. Montanaro G., Dichio B. Plant Water Relations: Absorption, Transport and Control Mechanisms, Advances in Selected Plant Physiology Aspects. Croatia: InTech, 2012, 388 p.

10. Demidchik V.V., Sokolik A.I., Jurin V.M. Uspehi sovremennoj biologii, 2001, vol. 121, no. 5, pp. 511-525. (in Russ.).

11. Rozencvet O.A., Murzaeva S.V., Gushhina I.A. Izvestija Samarskogo nauchnogo centra Rossijskoj akademii nauk, 2003, vol. 5, no. 2, pp. 305-311. (in Russ.).

12. Kosicyna A.A., Makurina O.N., Nesterov V.N., Rozencvet O.A. Izvestija Samarskogo nauchnogo centra Rossijskoj akademii nauk, 2010, vol. 12, no. 1, pp. 156-161. (in Russ.).

13. Dabahov M.V., Dabahova E.V., Titova V.I. Jekotoksikologija i problemy normirovanija. [Ecotoxicology and valuation issues]. N. Novgorod, 2005, 165 p. (in Russ.).

14. Kabata-Pendias A., Pendias X. Mikrojelementy v pochvah i rastenijah. [Trace elements in soils and plants]. Moscow, 1989, 439 p. (in Russ.).

15. Lebedev S.V., Osipova E.A., Korotkova A.M., Kuz'min S.N., Kudakaev I.R. Biologicheskaja nauka v reshenii problem estestvoznanija: materialy Vserossijskoj zaochnoj nauchno-prakticheskoj konferencii. [Biological science in solving the problems of natural science: Proceedings of the All-Russia correspondence scientific-practical conference]. Cheboksary, 2013, pp. 33-36. (in Russ.).

16. Shlyk A.A. Biochemistry, 1968, vol. 33, pp. 275-285.

17. GOST 30178-96. Syr'e i produkty pishhevye: atomno-sorbcionnyj metod opredelenija toksichnyh veshhestv [State Standard 30178-96. Raw materials and food: atomic-sorption method for the determination of toxic substances]. Minsk, 1997. (in Russ.).

18. Carter G.A., Knapp A.K. American Journal of Botany, 2001, no. 88, pp. 677-684.

19. Peshkova A.A., Dorofeev N.V. Vestnik IrGSHA, 2011, no. 45, pp. 20-27. (in Russ.).

20. Bitjuckij N.P. Mikrojelementy i rastenie: uchebnoe posobie. [Micronutrients and plant: a tutorial]. SPb, 1999, 232 p. (in Russ.).

21. Bingam F.T., Per'a F.D., Dzherell U.M. Nekotorye voprosy toksichnosti ionov metallov [Some questions toxicity of metal ions] / Ed. H. Zigelja, A. Zigelja. Moscow, 1993, pp. 101-131. (in Russ.).

22. Rico C.M., Majumdar S., Duarte-Gardea M., Peralta-Videa J.R., Gardea-Torresdey J.L. J. Agric Food Chem, 2011, no. 59(8), pp. 3485-3498. 